\title{
An Endemic Plant of Ermenek Region (Turkey), Muscari muscarmi: Economic Importance, and Is There a Useful Way Out Cultivation in Its Natural Habitats?
}

\author{
Haydar Oztas ${ }^{1}$, Fulya Oztas ${ }^{2}$, Mustafa Onur Aladağ ${ }^{2}$ and Ali Alaş ${ }^{1}$ \\ 1. A.K. Education Faculty, Necmettin Erbakan University, Meram, Konya 42000, Turkey \\ 2. Vocational High School, Selcuk University, Konya 42000, Turkey
}

\begin{abstract}
Turkey is one of the most floristically rich countries in the world with endemic plants. Approximately one third of its flora is endemic. The Muscari muscarimi which belongs to the Liliaceae family is one of its most prominent endemic geophyte plants which originates in southwestern of Turkey where it is found in rocky places like Ermenek, Başyayla (Büyükkarapınar village), Sariveliler. This species is the most sweetly scented member of the Liliaceae family, having something of the musk scent. Also, this plant locally is used in traditional medicine as antirheumatic, stomachic, diuretic and expectorant. In addition to this, it has also been used as food for humans and animals, ornamental plants in gardens. Morphologically, it has 3-6 linear-lanceolate, grayish-green leaves per plant and bulbs of $2-4 \mathrm{~cm}$ in diameter with thick fleshy perennial roots which delve down into the rocky ground of their natural habitats. The chemical is composed of polysaccharides, homoisoflavanons, glycosides etc. Main components of $M$. muscarimi were identified as (E)- $\beta$-ocimene (t-36\%), methyl salicylate (1-21\%), E-methyl isoeugenol (4-22\%) and benzyl benzoate (7-56\%). The picking up of the plant bulbs from their natural habitats is prohibited, in accordance with international agreements for the protection of endangered geophytes. The overly habitat destruction in native growing area threatened the existence of the species categories. It is known that in vitro bulblet production in Muscari muscarimi is low. This is difficult for its cultivation in native Ermenek area districts. Recent works show that the culturing immature Musari muscarimi embryos on different growth media could be considered as a useful method for in vitro propagation. As a result, the geophytes, such as M. muscarimi, are eligible widely for perfume production and in the pharmaceutical industry as well as for ornamental flowers. Because of this plant economic importance, bulbs growing and cultivation in their natural habitats could be discussed in this study.
\end{abstract}

Key words: Muscari muscarimi, Ermenek, endemic, propagation.

\section{Introduction}

Turkey is one of the most floristically rich countries in the world with endemic plants. The approximately one third of its flora is endemic. The Muscari muscarimi which belongs to the Liliaceae family is one of its most prominent endemic geophyte plants which originates in southwestern of Turkey where it is found in rocky places like Ermenek, Başyayla (Büyükkarapınar village), Sarıveliler.

It is a robust plant, with large bulbs which have

Corresponding author: Haydar Oztas, Ph.D., Dr., research field: aromatic plants \& experimental carcinogenesis. thick fleshy roots. Each bulb produces several greyish-green leaves. Flowers are borne in a spike or raceme. Individual flowers are 7-9 $\mathrm{mm}$ long, grey-white when fully open, sometimes with a bluish tone; they have a distinct scent of musk. This is the species from which the genus gets its name (Muscari is from the Greek muschos, meaning musk).

This species is the most sweetly scented member of the Liliaceae family, having something of the musk scent. Also, this plant locally is used in traditional medicine as antirheumatic, stomachic, diuretic and expectorant. In addition to this, it has also been used as food for humans and animals, ornamental plants in gardens. 


\section{Methods}

Morphologically, it has 3-6 linear-lanceolate, grayish-green leaves per plant and bulbs of $2-4 \mathrm{~cm}$ in diameter with thick fleshy perennial roots which delve down into the rocky ground of their natural habitats. The chemical is composed of polysaccharides, homoisoflavanons, glycosides and main components of $M$. muscarimi were identified as (E)- $\beta$-ocimene (t-36\%), methyl salicylate (1-21\%), E-methyl isoeugenol (4-22\%) and benzyl benzoate (7-56\%) [1].

Natural habitats are prohibited, in accordance with international agreements for the protection of endangered geophytes. The overly habitat destruction in native growing area threatened the existence of the species categories.

\section{Findings \& Discussion}

It is known that in vitro bulblet production in $M$. muscarimi is low. This is difficulty of its cultivation in native Ermenek area districts. Recent works show that the culturing immature M. muscarimi embryos on different growth media could be considered as a useful method for in vitro propagation.

The genus $M$. muscarimi is a species widely spread in Ermenek region. They locally grow and are known as "nergis". M. muscarimi have been used in traditional medicine as antirheumatic, stomachic, diuretic in this area. In addition to this, it has also been used as food for humans and animals, dye and as odor. The chemical composition of the M. Muscarimi is composed of anthocyanins, flavonoids, homoisoflavanones, spirocyclic nortriterpenoid glycosides and aromatic essential oil [1].

The picking up of the plant bulbs from their natural habitats is prohibited, in accordance with international agreements for the protection of endangered geophytes. The overly habitat destruction in native growing area threatened the existence of the species categories. It is known that in vitro bulblet production in M. muscarimi is low [2]. This is difficult for its cultivation in native Ermenek area districts.

Recent works show that the culturing immature $M$. muscarimi embryos on different growth media could be considered as a useful method for in vitro propagation.

As a result, the geophytes, such as M. Muscarimi is eligible widely for perfume production and in the pharmaceutical industry as well as for ornamental flowers. Because of this plant economic importance, bulbs growing and cultivation in their natural habitats could be important for regional resources.

\section{References}

[1] WCSP. 2011. World Checklist of Selected Plant Families, The Board of Trustees of the Royal Botanic Gardens, Kew, retrieved 2011-11-14, search for "Muscariracemosum".

[2] Jump up to: abMathew, Brian. 1987. The Smaller Bulbs, London: B.T. Batsford, ISBN978-0-7134-4922-8, p. 130 (under the name $M$. muscarimi) Jump upGarbari, F. \& Greuter, W. 1970. "On the Taxonomy and Typification of Muscari Miller (Liliaceae) and Allied Genera, and on the Typification of Generic Names." Taxon 19 (3): 329-35, doi:10.2307/1219056. 